\title{
PHYSIOLOGICAL RESPONSE OF LOCAL POPULATIONS OF SPECIES CYCLAMEN PURPURASCENS MILL. TO FOREST GAPS
}

\author{
RAVNJAK, B. ${ }^{1 *}-$ BAVCON, J. ${ }^{1}-$ OSTERC, G. ${ }^{2}$ \\ ${ }^{I}$ Department of Biology, Biotechnical Faculty, University Botanic Gardens Ljubljana, Ižanska \\ cesta 15, 1000 Ljubljana, Slovenia \\ (phone: +386-14-271-280) \\ ${ }^{2}$ Department of Agronomy, Biotechnical Faculty, University of Ljubljana, Jamnikarjeva 101, \\ 1000 Ljubljana, Slovenia \\ *Corresponding author \\ e-mail: blanka.ravnjak@bf.uni-lj.si; phone: +386-31-336-507 \\ (Received 20 $0^{\text {th }}$ Apr 2019; accepted $11^{\text {th }}$ Jul 2019)
}

\begin{abstract}
Aspect of forest dynamics is also the formation of forest gaps. Certain plant species typical for understory, still persists in newly formed forest gaps. For such species, environmental conditions change significantly. In research the physiological response of local populations of Cyclamen purpurascens Mill. in forest gaps, depending on time of their formation was examined. The physiological response was measured as anthocyanin and quercetin content in cyclamen leaves, depending on forest gap and season. It was found that anthocyanin content in leaves from all gaps was statistically higher in autumn than in spring. A comparison of anthocyanin content between leaves from different gaps has shown that leaves from the youngest gap in the spring contained a statistically lowest quantity of anthocyanin malvidin 3-rutinoside, malvidin 3-glucoside, and peonidin 3-Oneoheseridoside. There were no differences between other locations. For quercetins, it was found that leaves from the youngest gap in the spring contained the highest amount of myricetin-3-rhamnoside. Conclusion is that cyclamen leaves on the youngest gap have not yet completely adapted to increased solar radiation. Quercetins represent first and immediate response to increased UV-B radiation. Leaves on youngest gap in the spring do not yet have sufficient anthocyanin to protect them against radiation.
\end{abstract}

Keywords: anthocyanin, forest dynamics, light stress, quercetin, temperature stress

\section{Introduction}

Forests are one of the most common type of vegetation on the Earth. The layers, from top to ground, are as follows: canopy, understory, shrub layer, and herbaceous layer. A consequence of this stratification are also microclimatic conditions in individual layers. Moisture is thus highest by the forest floor due to evaporation from the ground, and the lowest slightly above the canopy, as air circulation is more intensive there (Smith and Smith, 2001). In terms of temperature, the highest is in the canopy layer, where solar radiation is the most intensive. Temperature then drops towards the floor. Another characteristic is the day and night cycle (generally, the temperature is lowest during the night) and the seasonal cycle in deciduous forests of the warm temperate climate. During spring months in such forests, the temperature is higher also in the organic layer, since canopies lack the leaves, allowing sufficient solar radiation to reach the floor. Increased temperature along the floor in the spring thus facilitates quick growth of spring geophytes (Smith and Smith, 2001; Schultze et al., 2005). Like the temperature, light intensity is also decreasing from top to bottom. In deciduous forests, only $5 \%$ of total solar light thus reaches the floor (Chazdon and Pearcy, 1991). 
Considering the lower exposure to light, plants of the herbaceous layer have various adaptations that enable efficient photosynthesis. They are capable of photosynthesis with the lowest solar radiation, utilising the light of longer wave lengths. While investing less energy into growing above-ground segments, they store more reserve food in underground plant organs, which in spring act as an additional source of food for the start of their growth (Whittaker, 1975). In plants that grow in the herbaceous layer while the canopy is leafed, photosynthetic activity mostly depends on sunflecks on the forest floor (Chazdon and Pearcy, 1991). Their leaf surfaces are larger, leaves are thinner, and have a poorly developed mesophyll tissue. They have only one layer of palisade tissue and a lower number of chloroplasts per surface unit, even though the quantity of chlorophyll in chloroplasts is higher than in leaves of plants growing in the sun. Thus, plants growing in the shade utilise to the highest possible degree the light reaching the undergrowth. Furthermore, they capture additional light with hypodermis and epidermis cells (Schultze et al., 2005; Lambers et al., 2008).

A forest gap caused by disturbances can lead tremendous stress as the sudden exposure to solar radiation for understory plants. Forest gaps are otherwise a normal occurrence and are part of the forest dynamic (Peterken, 1996). Compared to surrounding forest, temperature of floor and air, light intensity, and atmospheric humidity change to a greater extend in the area of a forest gap. Maximum light intensity in a gap is reached between $10 \mathrm{AM}$ and $2 \mathrm{PM}$, and is highest at the centre of the gap. Floor temperature is positively correlated to light intensity, growing from morning to evening in large gaps. In small and medium-sized gaps, floor temperature is the highest between 12 noon and 2 PM (Buajan et al., 2016). Due to the high quantity of sunlight, all plant species that lacked sufficient light for successful growth in the understory under the canopy cannot start to grow in such locations. Generally, the number of herbaceous species is higher on forest gaps than in understorey, and is positively correlated to the size of the gap (Collins and Pickett, 1988; Mihók, 2007). Furthermore, forest gaps represent a chance for forest stand regeneration. Individual trees that only stagnated in the herbaceous layer due to lack of light can accelerate their growth when a forest gap forms (Peterken, 1996).

The larger the forest gap, the greater the effect on local populations of plant species. At the same time, a formation of a forest gaps greatly affects understory plants that are otherwise adapted to weaker sunlight intensity under the canopy. Plants of the understory can respond to the formation of a forest gap, which for them represents stress, either as stress tolerant plants or by avoiding such stress. Shady plants have a lower response plasticity to the stress factor (Middleton, 2001). The adaptation can also manifest in a population reduction of a specific shady species, with only individual specimens thriving in microenvironments, where they are still somewhat protected by the shade of other plants. For instance, when studying the species turnover in forest gap formation, the population of species Galium odoratum Scop. was found to be smaller on a gap than in the forest. However, some species (Viola sylvestris Lam., Mercurialis perennis L.) have adapted to the changed environmental factors (Kelemen et al., 2012).

Substances that protect the plant against permanent damage and death are flavonoids. Their synthesis is induced by UV-B radiation through phytochrome (Caldwell et al., 1983). Flavonoids include anthocyanins, water-soluble pigments present in all plant tissues. Anthocyanins have a key role in protecting tissues against 
photo-inhibition and photo-oxidation (Chalker-Scott, 1999; Cooper-Driver, 2001; Gould et al., 2002; Ishizaka et al., 2002; Hughes et al., 2005, 2007; Hughes, 2011). They act as anti-oxidants that bind free radicals. This forms an anthocyaninperoxidase system that provides protection against oxidation damage (Yamasuki, 1997; Steyn et al., 2002). Anthocyanins are located in or just under the epidermis. Located closer to the upper side of the leaf, they act as a filter, reducing the level of inbound solar radiation. Anthocyanins thus protect the internal parts of the leaf primarily chloroplasts - against damage (Gould et al., 2000; Timmins et al., 2002). For this reason, they are - in this case - located above the chloroplasts. Plants growing in locations exposed to strong sunlight contain higher quantities of anthocyanins in leaves, stems, and flowers, compared to shady plants (Wheldale, 1916). In shady plants, they also accumulate in the lower epidermis, thus additionally participating in capturing sunlight (Chalker-Scott, 1999; Steyn et al., 2002). Anthocyanin synthesis is also light-induced; however, as opposed to other flavonoids, anthocyanins absorb sunlight in the visible part of the spectrum and less in the UV-B part (Caldwell et al., 1983; Mendez et al., 1999). Low temperatures under $25^{\circ} \mathrm{C}$ accelerate anthocyanin biosynthesis, while high temperatures over $35{ }^{\circ} \mathrm{C}$ cause their degradation and inhibit their accumulation (He et al., 2010). Furthermore, excessive UV-B radiation inhibits anthocyanin synthesis, likely due to DNA damage (Chalker-Scott, 1999). In addition to anthocyanins, quercetins are also very effective in binding reactive oxygen compounds. Their synthesis increases both in low and high radiation (Agati et al., 2012; Mierziak et al., 2014). The quantity of anthocyanins and quercetins can therefore act as an indicator whether or not a plant experienced light stress (was suddenly exposed to increased solar radiation), or if it has already adapted to increased solar radiation.

In our study, the physiological response of local populations of common cyclamen (Cyclamen purpurascens Mill.) in Dinaric fir-beech forest to increased exposure with solar radiation, as a result of forest gap formation, was examined. The common cyclamen as the subject of our study was chosen because it is one of the typical representatives of understory. Furthermore, it is a perennial plant, allowing us to measure the response of specific specimens to forest gaps, depending on the time from the gap formation, when they were exposed to increased solar radiation. By measuring anthocyanin and quercetin quantity in common cyclamen leaves, the response of specimens in local population was determined. A higher anthocyanin content in specimens of populations growing on older forest gaps, where plants have been exposed to a strong solar radiation for a longer period was predicted. Regardless of the location (forest gap), we predicted a lower anthocyanin quantity in leaves of all common cyclamen specimens during the spring, and higher quantity during late summer and autumn. Quercetin content was examined with the same purpose. A higher quercetin quantity in leaves of specimens growing on older forest gaps was predicted.

\section{Material and methods}

\section{Experiment design}

In the study 6 sampling locations were included, where five represented forest gaps in Dinaric fir-beech forests (Omphalodo-Fagetum) that naturally formed at different times and one sampling location that represented juvenile phase of beech forest. All 
sampling locations were located in the Dinaric biogeographic macro-region in the southern part of Slovenia (Kočevska Region) (Wraber, 1969) (Figs. 1 and 2; Table 1).



Figure 1. Research area in Kočevska region (marked with red square), with detailed map of 6 sampling locations (forest gaps in Dinaric fir-beech forests)



Figure 2. Photographs of all sampling locations (SL1 - Kamen zid, SL2 - Below Barnikom, SL3 - Above Barnikom, SL4 - Below Goteniški Snežnik, SL5 - Goteniška gora, SL6 - Above Draga) 
Table 1. Sampling locations and their features (coordinates, UTM quadrant, altitude, exposure, substrate, soil). The sampling location marked * contains juvenile phase of beech forest

\begin{tabular}{c|c|c|c|c|c|c|c}
\hline Sampling location & Coordinates & UTM & Altit. & Exp. & Surface & Substrate & Soil \\
\hline SL1 (Kamen Zid)* & $\begin{array}{c}\text { Y: } 5479575 \\
\text { X: } 5052223\end{array}$ & VL75 & $1068 \mathrm{~m}$ & SE & $175 \mathrm{~m}^{2}$ & Limestone & Rendzina \\
\hline SL2 (Below Barnik) & $\begin{array}{c}\text { Y: } 5478774 \\
\text { X: } 5051499\end{array}$ & VL75 & $1132 \mathrm{~m}$ & SW & $600 \mathrm{~m}^{2}$ & Dolomite & Rendzina \\
\hline SL3 (Above Barnik) & $\begin{array}{c}\text { Y: } 5478904 \\
\text { X: } 5051210\end{array}$ & VL75 & $1161 \mathrm{~m}$ & SE & $1400 \mathrm{~m}^{2}$ & $\begin{array}{c}\text { Limestone, } \\
\text { dolomite }\end{array}$ & Rendzina \\
\hline SL4 (Below Goteniški Snežnik) & $\begin{array}{l}\text { Y: } 5480085 \\
\text { X: } 5049403\end{array}$ & VL74 & $1205 \mathrm{~m}$ & $\mathrm{E}$ & $1300 \mathrm{~m}^{2}$ & $\begin{array}{c}\text { Limestone, } \\
\text { dolomite }\end{array}$ & Rendzina \\
\hline SL5 (Goteniška gora) & $\begin{array}{l}\text { X: } 5055948 \\
\text { Y: } 5476338\end{array}$ & VL5 & $1100 \mathrm{~m}$ & SE & $3200 \mathrm{~m}^{2}$ & $\begin{array}{c}\text { Limestone, } \\
\text { dolomite }\end{array}$ & Rendzina \\
\hline SL6 (Above Draga) & $\begin{array}{l}\text { Y: } 5473400 \\
\text { X: } 5052341\end{array}$ & VL5 & $954 \mathrm{~m}$ & $\mathrm{E}$ & $1480 \mathrm{~m}^{2}$ & Dolomite & Rendzina \\
\hline
\end{tabular}

This biogeographic region is characterised by the contact of Sub-Mediterranean climate and the temperate continental climate of western and southern Slovenia, resulting in large quantities of precipitation in this region (between 1,400 and $3,500 \mathrm{~mm}$ ) (Fig. 3), with a distinct autumn maximum and indistinct spring maximum (Kordiš, 1993). A thick snow cover is also characteristic, and can persist long into spring due to low temperatures. Average annual temperatures in the region are between $5{ }^{\circ} \mathrm{C}$ and $8{ }^{\circ} \mathrm{C}$ (Fig. 4). Temperature decreases with altitude, with characteristic temperature inversion in certain areas. Beside the data for whole area we also made temperature measurements at the biggest sampling location (Goteniška gora) from May to end of December in year 2016 (Fig. 5). At the end of July (because of the peak of year radiation) on sunny day measurements of UV-B radiation at all sampling sites between 9:00 and 15:00 were done. Radiation was measured in transect in the middle of localities (forest gaps) and at two opposite edges (on junctures with forest). Measurements were done by Digital Ultraviolet Radiometer Model 6.2. UVB by Solarmeter USA (Fig. 6).

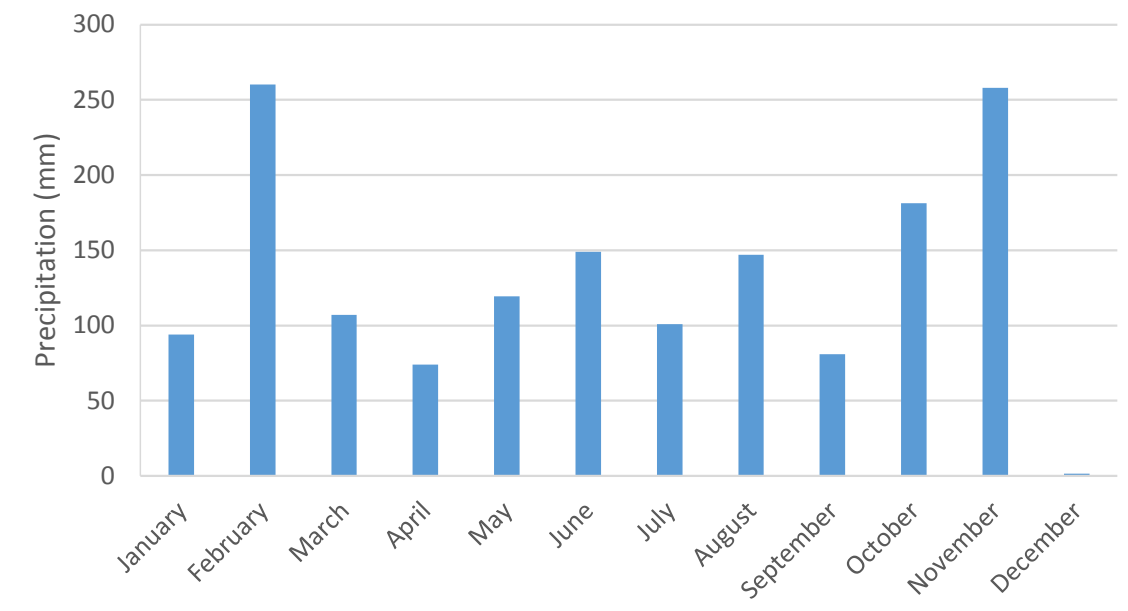

Figure 3. Mean month precipitation for Kočevska region, measured at climatic station. (Data source: Slovenian Environment Agency - ARSO) 


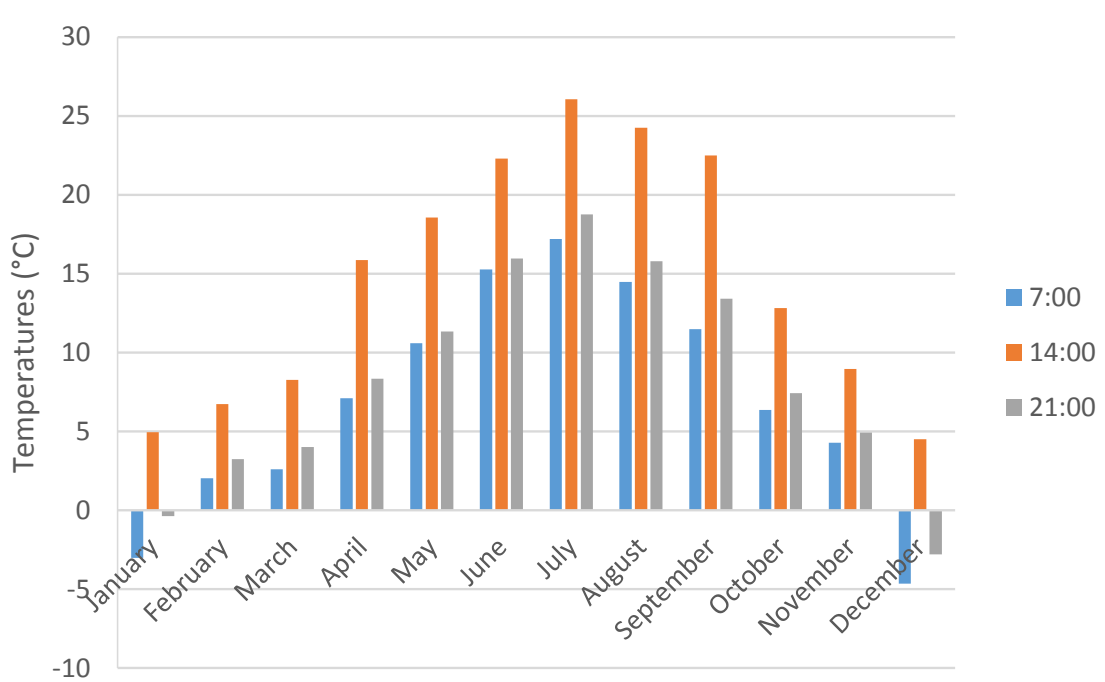

Figure 4. Mean month temperatures for Kočevska region (measurement times at 7:00, 14:00 and 21:00), measured at climatic station. (Data source: Slovenian Environment Agency ARSO)

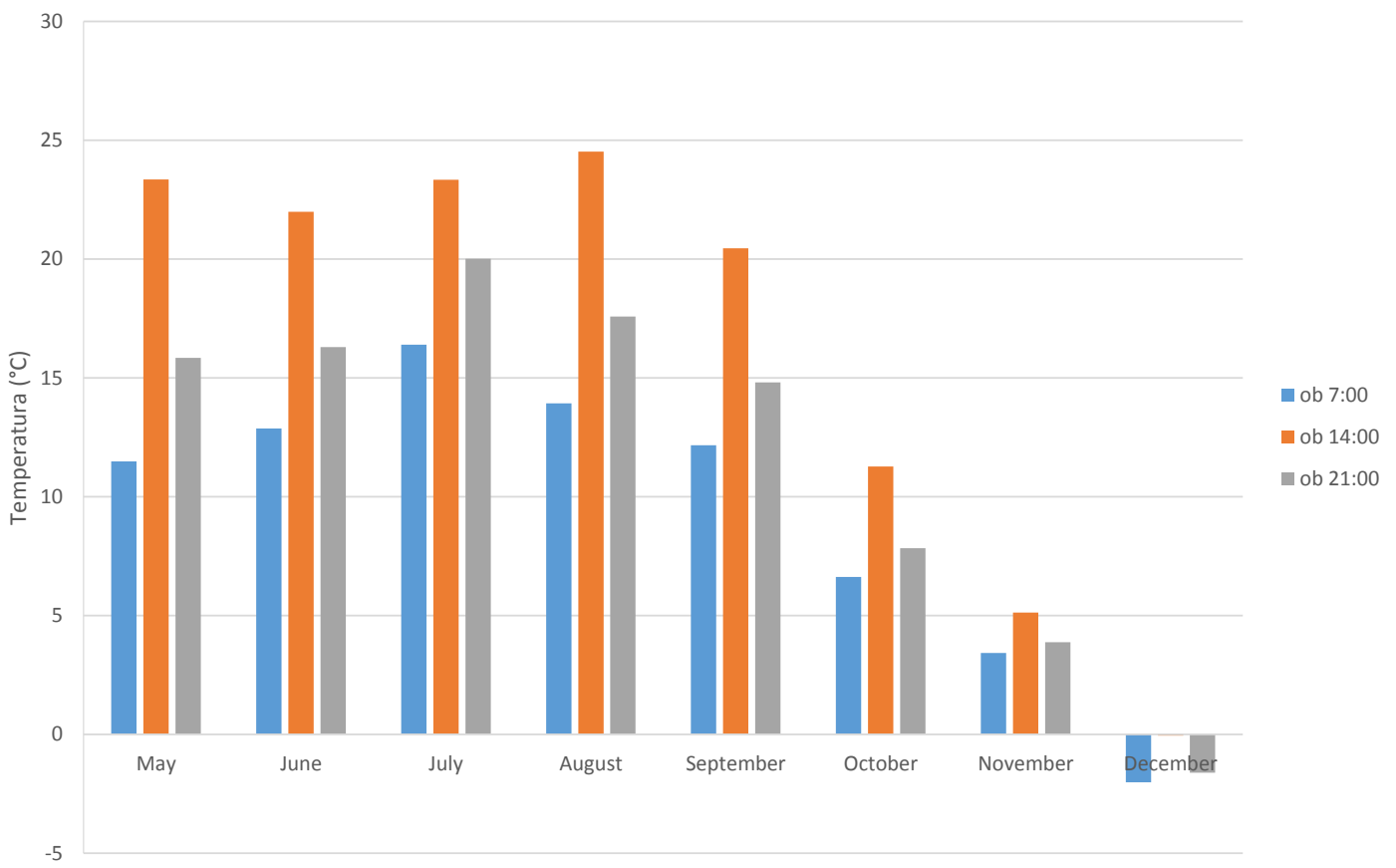

Figure 5. Mean month temperatures measured at location Goteniška gora in year 2016 (measurement times at 7:00, 14:00 and 21:00)

\section{Leaf sampling for anthocyanin and quercetin analyses}

The common cyclamen is a widespread species in Slovenia (Bavcon, 2009). It is a geophyte representative, as it has an underground tuber that represents a food storage tissue (Grey-Wilson, 2002). Its leaves are evergreen and whither in summer months before flowering. After flowering, new leaves begin growing (Bavcon, 2009). Leaves contain anthocyanins on their abaxial side, which in most cases give leaves a purple 
colour (Grey-Wilson, 2002). Common cyclamen specimens that grow in the shade have a more intensely coloured purple leaves (Kerner, 1894). An even more intense purple colour can be found on leaves of specimens growing in locations with strong solar radiation exposure (Grey-Wilson, 1988, 2002; Mathew, 2013).

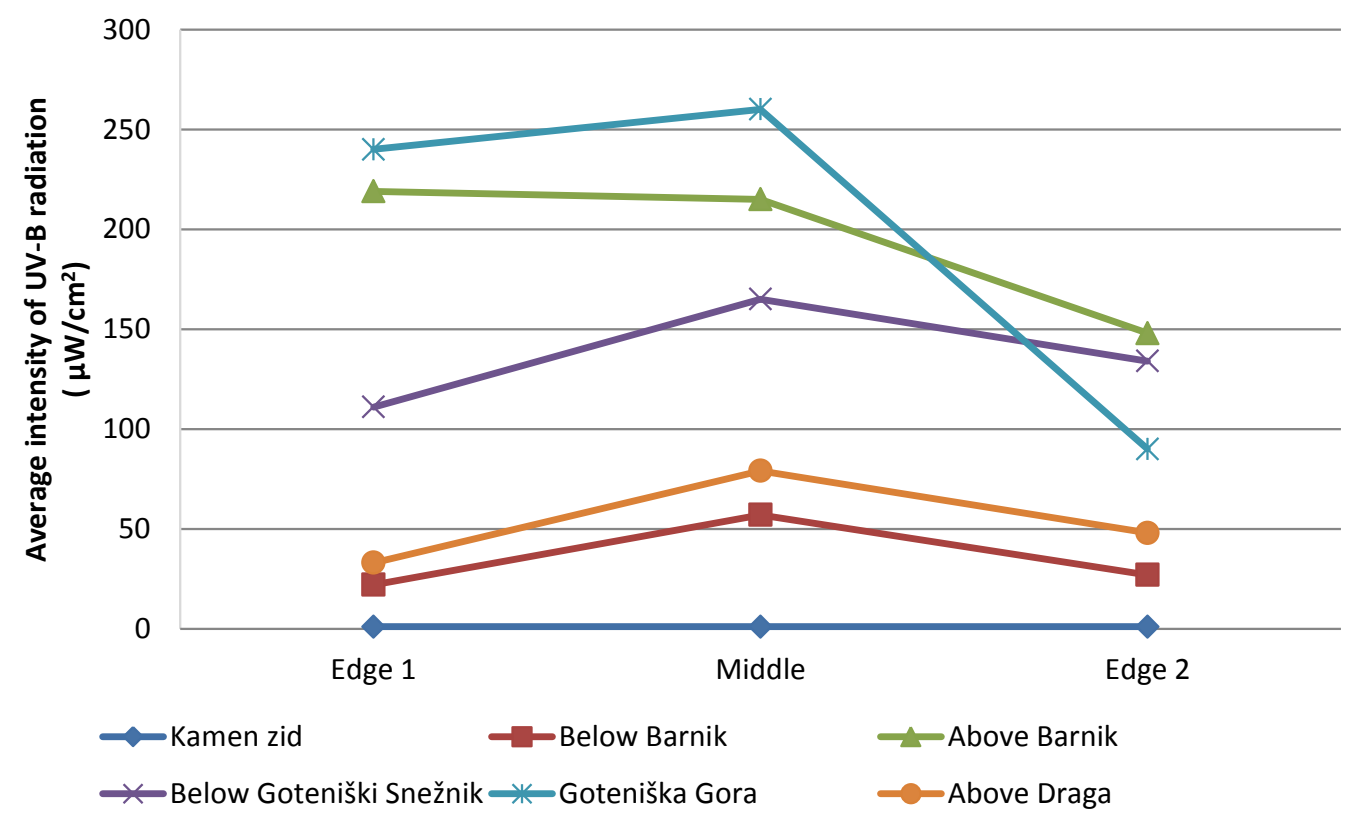

Figure 6. Average intensity of $U V-B$ radiation at sampling localities, measured at the end of July 2016 (Middle - middle of the gap/locality, Edge 1 - first edge of the gap/locality, Edge 2 second edge of gap/locality)

In year 2016 all leaves from three to six plants from all 6 sampling locations (depending on the abundance of specimens in the local populations) were removed, put in plastic bags, and stored in a portable cooling container. During spring, we did not find any common cyclamen leaves in sampling locations Goteniška gora and Below Goteniški Snežnik, because leaves had died of hard conditions during winter. During late summer, only one cyclamen leaf at the sampling location Above Barnik was found, in which we measured the anthocyanin content. This sample was not included in further statistical analysis. The leaves taken in spring were not from the same specimens then leaves taken in late summer. Cyclamen leaves were then frozen until further processing in a freezer at $-18{ }^{\circ} \mathrm{C}$. Cyclamen leaves were collected in April and then once again in late August (Table 2).

\section{Anthocyanin and quercetin content measurements}

Each leaf was ground in liquid nitrogen before the powder was mixed with $2 \mathrm{ml}$ of extraction solution ( $3 \%$ formic acid $+\%$ methanol), and the anthocyanins were extracted for $1 \mathrm{~h}$ in an ice ultrasonic bath. The samples were then centrifuged for $7 \mathrm{~min}$ at $12.000 \times \mathrm{g}$, filtered through Chromafil AO-20/25 polyamide filters into vials, and stored until HPLC-MS analyses in the freezer at $-20{ }^{\circ} \mathrm{C}$ (Osterc et al., 2014).

Phenolic compounds were analysed on a Thermo Finnigan Surveyor HPLC system (Thermo Scientific, San Jose, USA) with a diode array detector at $350 \mathrm{~nm}$ (flavonols) and $530 \mathrm{~nm}$ (anthocyanins). Spectra of the compounds were recorded between 200 and 
$600 \mathrm{~nm}$. The column was a Gemini C18 (150 mm×4.6 mm $3 \mu \mathrm{m}$; Phenomenex, Torrance, USA) operated at $25{ }^{\circ} \mathrm{C}$. The elution solvents were aqueous $0.1 \%$ formic acid in double distilled water (A) and $0.1 \%$ formic acid in acetonitrile (B). Samples were eluted according to a linear gradient from $5 \%$ to $20 \%$ B in the first $15 \mathrm{~min}$, followed by a linear gradient from $20 \%$ to $30 \%$ B for $5 \mathrm{~min}$, then an isocratic mixture for $5 \mathrm{~min}$, followed by a linear gradient from $30 \%$ to $90 \% \mathrm{~B}$ for $5 \mathrm{~min}$, and then an isocratic mixture for $15 \mathrm{~min}$ before returning to the initial conditions. The injection amount was $20 \mu 1$ and flow rate $0.6 \mathrm{~mL} \mathrm{~min}^{-1}$ (Osterc et al., 2014).

Table 2. Numbers of samples taken per one location in each of two seasons

\begin{tabular}{c|c|c}
\hline Sampling location & No. of samples (spring) & $\begin{array}{c}\text { No. of samples (late } \\
\text { summer) }\end{array}$ \\
\hline SL1 (Kamen Zid) & 8 & 0 \\
SL2 (Below Barnik) & 15 & 13 \\
SL3 (Above Barnik) & 9 & 1 \\
SL4 (Below Goteniški Snežnik) & 0 & 15 \\
SL5 (Goteniška gora) & 0 & 10 \\
SL6 (Above Draga) & 18 & 18 \\
\hline
\end{tabular}

All phenolic compounds were identified by a HPLC-Finnigan MS detector and an LCQ Deca XP MAX (Thermo Finigan, San Jose, CA) instrument with electrospray interface (ESI) operating in positive (for anthocyanins) and negative (other phenolic groups) ion mode. The analyses were carried out using full scan data-dependent $\mathrm{MS}^{\mathrm{n}}$ scanning from $\mathrm{m} / \mathrm{z}, 110$ to 1500 . Column and chromatographic conditions were identical to those used for the HPLC-DAD analyses. The injection volume was $10 \mu \mathrm{L}$ and the flow rate maintained at $0.6 \mathrm{~mL} \mathrm{~min}^{-1}$. The capillary temperature was $250{ }^{\circ} \mathrm{C}$, the sheath gas and auxiliary gas were 60 and 15 units, respectively; the source voltage was $3 \mathrm{kV}$ for negative ionisation and $4 \mathrm{kV}$ for positive ionisation and normalised collision energy was between 20 and 35\%. Spectral data were elaborated using the Excalibur software (Thermo Scientific). The identification of compounds was confirmed by comparing retention times and their spectra as well as by adding the standard solution to the sample and by fragmentation.

Content of the following anthocyanins and quercetins was determined:

Anth1 = Malvidin-3, 5-diglucoside, Anth2 = Cyanidin-3-neohesperidoside, Anth3 = Malvidin-3-rutinoside, Anth4 = Malvidin-3-glucoside, Anth5 = Peonidin-3O-neoheseridoside

Comp1 = Quercetin di rhamnosyl hexoside1 expressed as Quercetin-3-rutinoside, Comp2 = Quercetin di rhamnosyl hexoside2 expressed as Quercetin-3-rutinoside, Comp3 = Myricetin-3-rutinoside expressed as Myricetin-3-rhamnnoside, Comp4 $=$ Myricetin-hexoside expressed as Myricetin-3-rhamnoside, Comp5 = Kaempferol dirhamnosyl hexoside expressed as Kaempferol-glucoside, Comp6 = Quercetin-3-rutinoside, Comp7 = Laricitin-3-O-rutinoside expressed as Quercetin-galaktoside,$\quad$ Comp8 = Myricetin-3-rhamnoside,$\quad$ Comp9 = Quercetin-3galactoside, Comp10 = Kaempferol 3-rutinoside expressed as Kaempferol-glucoside, Comp11 = Isorhamnetin-3-rutinoside expressed as Isorhamnetin-glucoside, Comp12 = Quercetin-3-rhamnoside, $\quad$ Comp13 $=$ Neohesperidoside expressed as Quercetin-3-galactoside 


\section{Statistical analysis}

The effects of location and time were assessed by Two-way ANOVA followed by Duncan's multiple range test with a 95\% confidence interval for the comparison of the mean values of anthocyanin and quercetin contents. We used the statistical programme Statgraphics-Plus. Uneven sample size was handled by automatic approximation of statistical program.

\section{Results}

\section{Anthocyanins}

Higher quantities of all anthocyanins of leaves collected in late summer compared to leaves collected in spring (Fig. 7) was found. Of leaves collected in spring, the highest anthocyanin content was measured in those collected at locations Kamen Zid and Above Barnik. In terms of anthocyanin quantity in the spring, leaves from all locations combined had the higher quantities of malvidin-3,5-diglucoside $\left(196.6 \pm 122.8 \mu \mathrm{g} \mathrm{g}^{-1}\right)$ and malvidin 3-rutinoside $\left(69.7 \pm 74.5 \mu \mathrm{g} \mathrm{g}^{-1}\right)$ (Fig. 7). When comparing anthocyanin content quantities in cyclamen leaves from different locations, no statistically significant differences were found for malvidin-3,5-diglucoside and cyaniding-3neohesperidoside. For anthocyanins malvidin-3-rutinoside, malvidin-3-glucoside, and peonidin-3-O-neoheseridoside, there were statistically significant differences in content quantities for all three compounds between locations Above Barnik (Fig. 8) and Above Draga, as well as Above Draga and Kamen Zid. In both cases, leaves collected at location Above Draga contained significantly lower quantity of anthocyanins compared to leaves collected at the other two locations (Fig. 8; Table 3).

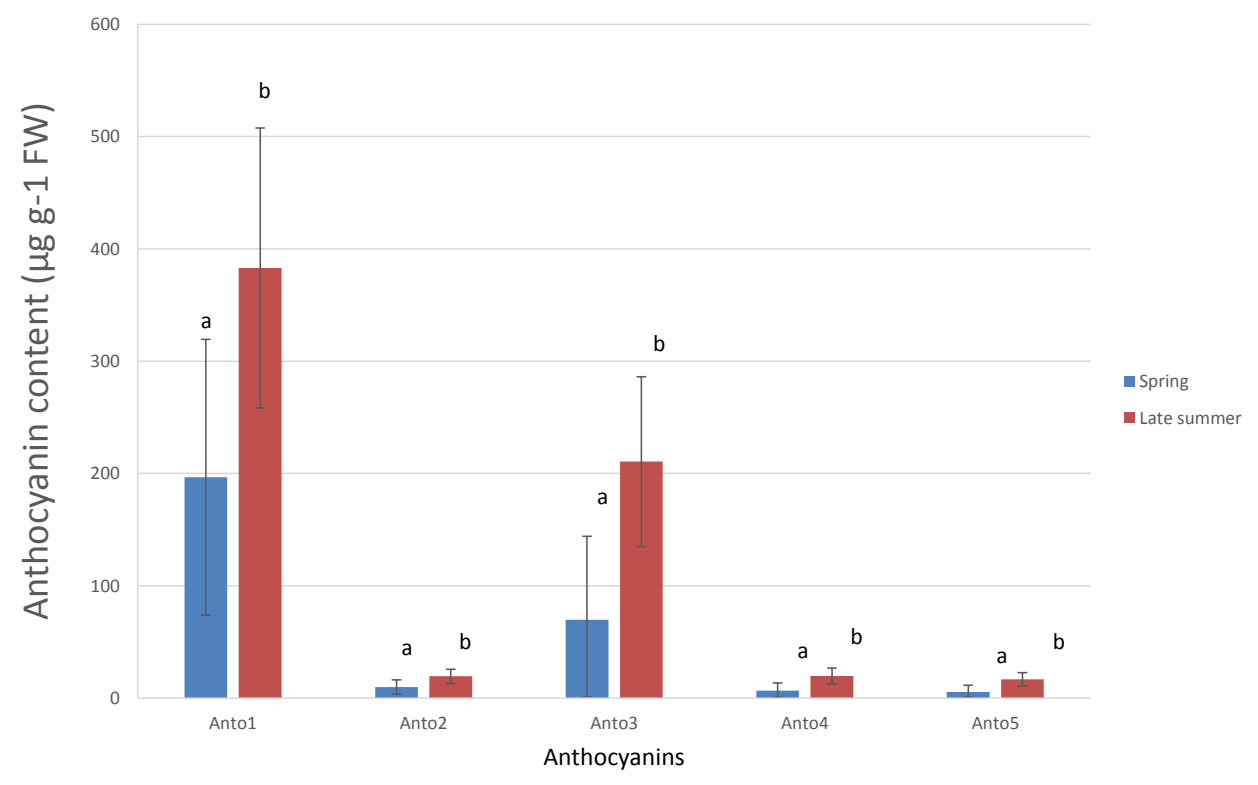

Figure 7. Mean values, upper and lower anthocyanin content limits in cyclamen leaves collected in spring and late summer. With a $95 \%$ confidence interval and $P \leq 0.05$. Characters $a$ and $b$ are used to mark statistically significant differences in content of specific anthocyanins between spring and late summer samples (Anth1 = Malvidin-3,5-diglucoside, Anth2 = Cyanidin-3-neohesperidoside, Anth3 = Malvidin-3-rutinoside, Anth4 = Malvidin-3glucoside, Anth5 = Peonidin-3-O-neoheseridoside) 
Table 3. Mean values, upper and lower anthocyanin content limits in cyclamen leaves collected in spring (Sp.) and late summer (Su.) at 6 locations (SL1 = Goteniška gora, SL2 = Above Barnik, 3 = Below Barnik, 4 = Above Draga, 5 = Below Goteniški Snežnik, $S L 6=$ Kamen zid)

\begin{tabular}{c|c|c|c|c|c|c|c|c|c|c|c|c|c}
\hline \multirow{2}{*}{ Locality } & \multicolumn{2}{c|}{ SL1 } & \multicolumn{2}{c|}{ SL2 } & \multicolumn{2}{c|}{ SL3 } & \multicolumn{2}{c|}{ SL4 } & \multicolumn{2}{c|}{ SL5 } & \multicolumn{2}{c}{ SL6 } \\
\cline { 2 - 14 } & Sp. & Su. & Sp. & Su. & Sp. & Su. & Sp. & Su. & Sp. & Su. & Sp. & Su. \\
\hline \multirow{4}{*}{ Anth1 } & Upp. & $/$ & 955.6 & 292.3 & 683.6 & 133.9 & 521.1 & 135.4 & 549.5 & $/$ & 557.9 & 213.8 & $/$ \\
& Mean & $/$ & $\mathbf{6 4 1 . 4}$ & $\mathbf{1 7 1 . 8}$ & $\mathbf{3 0 8 . 7}$ & $\mathbf{9 2 . 7}$ & $\mathbf{2 3 6 . 4}$ & $\mathbf{1 0 0 . 5}$ & $\mathbf{3 4 0 . 4}$ & $/$ & $\mathbf{3 0 0 . 4}$ & $\mathbf{1 5 3 . 7}$ & $/$ \\
& Low. & $/$ & 327.3 & 51.2 & & 51.5 & & 65.7 & 131.2 & $/$ & 42.9 & 93.6 & $/$ \\
\hline \multirow{4}{*}{ Anth2 2} & Upp. & $/$ & 48.3 & 14.8 & 34.6 & 6.8 & 26.4 & 6.8 & 27.8 & $/$ & 28.3 & 10.8 & $/$ \\
& Mean & $/$ & $\mathbf{3 2 . 4}$ & $\mathbf{8 . 7}$ & $\mathbf{1 5 . 6}$ & $\mathbf{4 . 7}$ & $\mathbf{1 1 . 9}$ & $\mathbf{5 . 1}$ & $\mathbf{1 7 . 2}$ & $/$ & $\mathbf{1 5 . 2}$ & $\mathbf{7 . 8}$ & $/$ \\
& Low. & $/$ & 16.6 & 2.6 & 0 & 2.6 & 0 & 3.3 & 6.6 & $/$ & 2.2 & 4.7 & $/$ \\
\hline \multirow{4}{*}{ Anth3 3.6} & Upp. & $/$ & 509.8 & 140.7 & 454.3 & 58.0 & 308.0 & 43.4 & 329.3 & $/$ & 294.3 & 108.9 & $/$ \\
& Mean & $/$ & $\mathbf{3 2 8 . 1}$ & $\mathbf{7 9 . 3}$ & $\mathbf{1 1 9 . 7}$ & $\mathbf{3 7 . 0}$ & $\mathbf{1 4 3 . 4}$ & $\mathbf{2 5 . 6}$ & $\mathbf{2 0 8 . 3}$ & $/$ & $\mathbf{1 4 5 . 3}$ & $\mathbf{7 8 . 3}$ & $/$ \\
& Low. & $/$ & 146.3 & 17.8 & 0 & 16.0 & 0 & 7.9 & 87.3 & $/$ & 0 & 47.6 & $/$ \\
\hline \multirow{4}{*}{ Anth4 4} & Upp. & $/$ & 47.9 & 13.2 & 42.7 & 5.6 & 28.9 & 4.1 & 30.9 & $/$ & 27.6 & 10.2 & $/$ \\
& Mean & $/$ & $\mathbf{3 0 . 8}$ & $\mathbf{7 . 5}$ & $\mathbf{1 1 . 3}$ & $\mathbf{3 . 5}$ & $\mathbf{1 3 . 5}$ & $\mathbf{2 . 4}$ & $\mathbf{1 9 . 6}$ & $/$ & $\mathbf{1 3 . 7}$ & $\mathbf{7 . 4}$ & $/$ \\
& Low. & $/$ & 13.8 & 1.7 & 0 & 1.6 & 0 & 0.7 & 8.2 & $/$ & 0 & 4.5 & $/$ \\
\hline \multirow{4}{*}{ Anth5 } & Upp. & $/$ & 40.4 & 11.1 & 35.9 & 4.6 & 24.4 & 3.4 & 26.1 & $/$ & 23.3 & 8.6 & $/$ \\
& Mean & $/$ & $\mathbf{2 5 . 9}$ & $\mathbf{6 . 3}$ & $\mathbf{9 . 5}$ & $\mathbf{2 . 9}$ & $\mathbf{1 1 . 3}$ & $\mathbf{2 . 0}$ & $\mathbf{1 6 . 5}$ & $/$ & $\mathbf{1 1 . 5}$ & $\mathbf{6 . 2}$ & $/$ \\
& Low. & $/$ & 11.6 & 1.4 & 0 & 1.3 & 0 & 0.6 & 6.9 & $/$ & 0 & 3.8 & $/$ \\
\hline
\end{tabular}

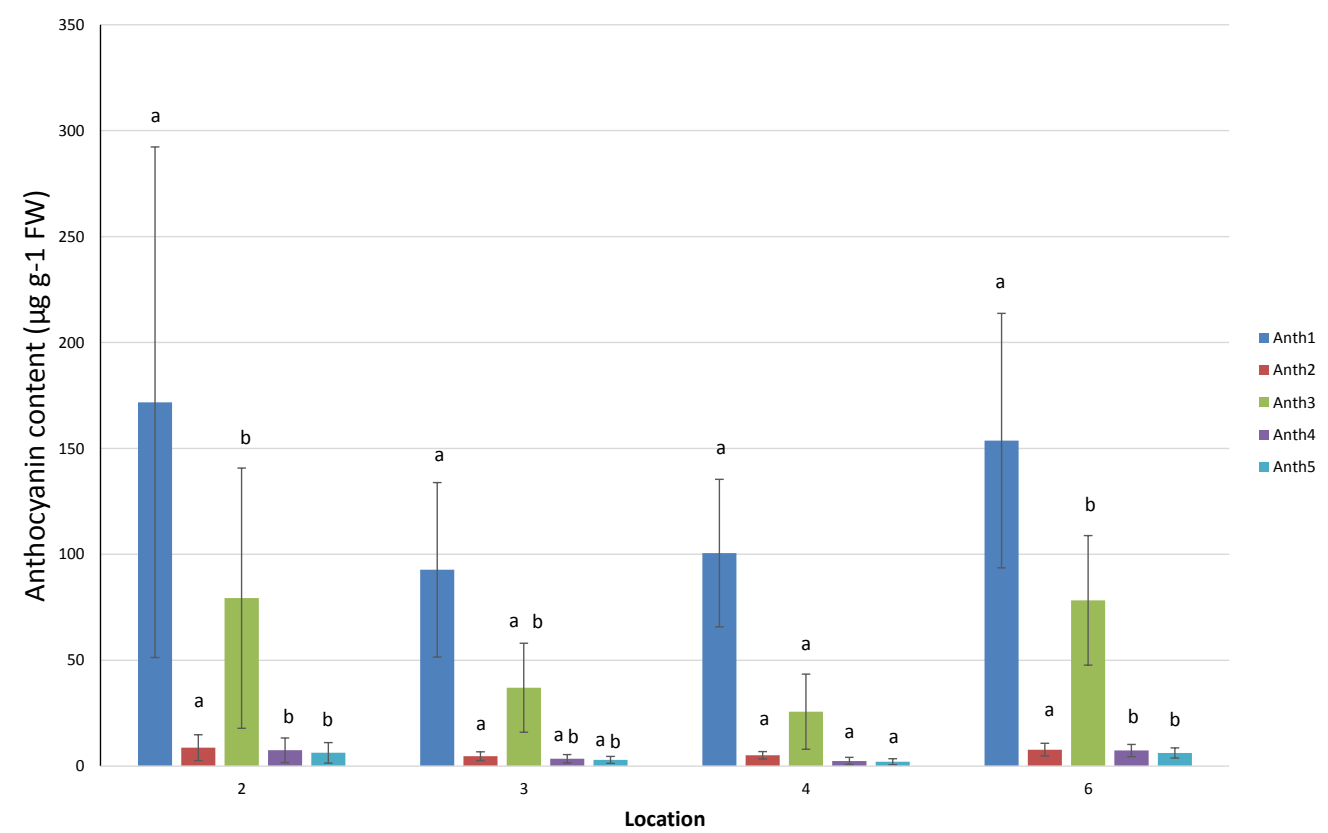

Figure 8. Mean values, upper and lower anthocyanin content limits in cyclamen leaves collected in spring at various sampling locations $(2=$ Above Barnik, $3=$ Below Barnik, $4=$ Above Draga, $6=$ Kamen Zid). With a 95\% confidence interval and $P \leq 0.05$. Characters a and $b$ are used to mark statistically significant differences in anthocyanin content of between individual locations $\mathbf{A n t h 1}=$ Malvidin 3,5-diglucoside, Anth2 $=$ Cyanidin 3-neohesperidoside,

Anth3 = Malvidin 3-rutinoside, Anth4 = Malvidin 3-glucoside, Anth5 = Peonidin 3-Oneoheseridoside) 
During late summer, the highest anthocyanin content was of leaves collected at location Goteniška gora and the lowest in those collected at location Below Barnik. Even in late summer, malvidin-3, 5-diglucoside (383.1 $\left.\pm 124.7 \mu \mathrm{g} \mathrm{g}^{-1}\right)$ and malvidin-3rutinoside $\left(210.6 \pm 75.6 \mu \mathrm{g} \mathrm{g}^{-1}\right)$ were predominant for all locations combined (Fig. 9). When comparing anthocyanin content in leaves from various locations, a statistically significant difference in late summer samples for anthocyanins malvidin-3, 5diglucoside and cyanidin-3-neohesperidoside, specifically only between locations Goteniška gora and Below Barnik (Fig. 9) was found. So, statistically significant differences were between Goteniška gora as a oldest and largest forest gap on which temperature fluctuation are the highest (Fig. 4), and Below Barnik as smallest forest gap where the effect of forest edge was expressed (shading and slipstream because of trees).



Figure 9. Mean values, upper and lower anthocyanin content limits in cyclamen leaves collected in late summer at various sampling locations $(1=$ Goteniška gora, $2=$ Above Barnik, $3=$ Below Barnik, 4 = Above Draga, 5 = Below Goteniški Snežnik). With a 95\% confidence interval and $P \leq 0.05$. Character $a$ and $b$ is used to mark statistically significant differences in anthocyanin content between individual locations (Anth1 = Malvidin 3,5-diglucoside, Anth2 = Cyanidin 3-neohesperidoside, Anth3 = Malvidin 3-rutinoside, Anth4 = Malvidin 3glucoside, Anth5 = Peonidin 3-O-neoheseridoside)

\section{Quercetins}

A comparison of quercetin content between spring and late summer cyclamen leaves showed a statistically significant higher content in late summer leaves for the following quercetins: quercetin di rhamnosyl hexoside2, quercetin-3-rutinoside, laricitin-3-Orutinoside, myricetin-3-rhamnoside, and quercetin-3-galactoside. For quercetin di rhamnosyl hexoside and Myricetin-3-rutinoside content was higher in spring, but there were no statistically significant differences in content between seasons for the rest of the quercetins. When analysing the late summer quercetin content in cyclamen leaves from various locations, we measured the highest content in all leaves for quercetin-dirhamnosyl hexoside2 $\quad\left(4050.5 \pm 2413.9 \quad \mu \mathrm{g} \quad \mathrm{g}^{-1}\right), \quad$ quercetin-3-rutinoside 
$\left(6129.7 \pm 2961.2 \mu \mathrm{g} \mathrm{g}^{-1}\right)$, and myricetin-3-rhamnoside $\left(1721.6 \pm 1014.6 \mu \mathrm{g} \mathrm{g}^{-1}\right)($ Figs. 8 and 9). Statistically significant difference in quercetin content in leaves for as many as eight quercetins between locations Above Barnik and Below Barnik was found. Quercetin quantity in leaves collected Above Barnik most often differed from other locations; in addition to the abovementioned, also from locations Above Draga (yungest gap) and Kamen Zid (juvenile beech forest). Quercetin quantities kaempferol dirhamnosyl hexoside and neohesperidoside most often differed with a statistical significance between locations Above Barnik and Below Barnik, Above Barnik and Above Draga, Above Barnik and Kamen Zid, and Below Barnik and Kamen Zid. While quercentin contents for quercetin-3-galactoside in kaempferol 3-rutinoside differed with a statistical significance between the following locations: Above Barnik and Below Barnik, Above Barnik and Kamen Zid, Below Barnik and Above Draga, and Below Barnik and Kamen Zid, contents of laricitin-3-O-rutinoside and myricetin-3-rhamnoside differed with a statistical significance between locations Above Barnik and Above Draga, Below Barnik and Above Draga, and Above Draga and Kamen Zid. In spring samples, no statistically significant differences based on sampling location for quercetin di rhamnosyl hexoside2 and quercetin-3-rhamnoside (Figs. 10 and 11; Table 4) was found.

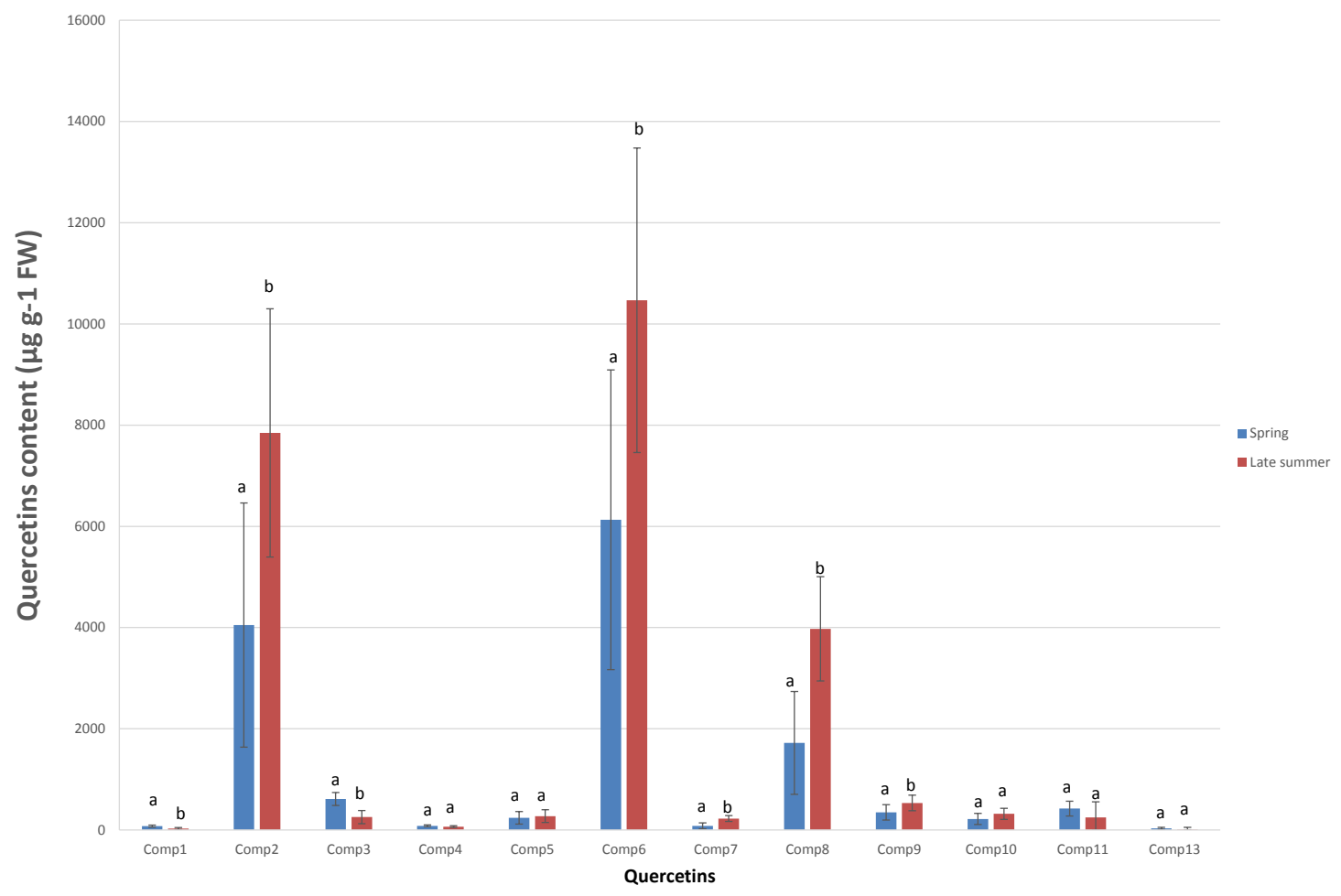

Figure 10. Mean values, upper and lower quercetin content limits in cyclamen leaves collected in spring and late summer. With a 95\% confidence interval and $P \leq 0.05$. Characters $a$ and $b$ are used to mark statistically significant differences in content of specific quercetins between spring and late summer samples $($ Comp $1=$ Quercetin di rhamnosyl hexoside,

Comp2 = Quercetin di rhamnosyl hexoside2, Comp3 = Myricetin-3-rutinoside,

Comp4 = Myricetin-hexoside, Comp5 = Kaempferol dirhamnosyl hexoside,

Comp6 $=$ Quercetin-3-rutinoside, Comp7 $=$ Laricitin-3-O-rutinoside, Comp8 $=$ Myricetin-3rhamnoside, Comp9 $=$ Quercetin-3-galactoside, Comp10 $=$ Kaempferol 3-rutinoside,

Comp11 = Isorhamnetin-3-rutinoside, Comp13 = Neohesperidoside) 
Table 4. Mean values, upper and lower quercetin content limits in cyclamen leaves collected in spring (Sp.) and late summer (Su.) at 6 locations ( $S L 1=$ Goteniška gora, SL2 = Above Barnik, 3 = Below Barnik, 4 = Above Draga, $5=$ Below Goteniški Snežnik, SL6 = Kamen zid)

\begin{tabular}{|c|c|c|c|c|c|c|c|c|c|c|c|c|c|}
\hline \multirow{2}{*}{\multicolumn{2}{|c|}{ Locality }} & \multicolumn{2}{|c|}{ SL1 } & \multicolumn{2}{|c|}{ SL2 } & \multicolumn{2}{|c|}{ SL3 } & \multicolumn{2}{|c|}{ SL4 } & \multicolumn{2}{|c|}{ SL5 } & \multicolumn{2}{|c|}{ SL6 } \\
\hline & & Sp. & Su. & Sp. & Su. & Sp. & Su. & Sp. & Su. & Sp. & Su. & Sp. & Su. \\
\hline \multirow{3}{*}{ Comp1 } & Upp. & 1 & 63.6 & 59.1 & 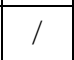 & 101.1 & 53.2 & 77.0 & 48.2 & 1 & 78.0 & 85.6 & 1 \\
\hline & Mean. & I & 26.1 & 36.7 & I & 83.8 & 17.4 & 61.6 & 22.1 & I & 45.4 & 60.2 & I \\
\hline & w. & I & 0.0 & 14.3 & I & 66.5 & 0.0 & 46.2 & 0.0 & I & 12.7 & 34.9 & I \\
\hline \multirow{3}{*}{ Comp2 } & & I & 18002.5 & 1 & I & I & 12107.4 & I & 11902.5 & I & 14388.6 & 1 & I \\
\hline & ean. & I & 11526.8 & I & I & I & 5922.0 & I & 7406.7 & I & 8752.8 & I & I \\
\hline & Low. & 1 & 5051.2 & 1 & 1 & 1 & 0.0 & I & 2910.9 & 1 & 3117.0 & 1 & I \\
\hline \multirow{3}{*}{ Comp3 } & pp. & I & & \begin{tabular}{|l|}
472.9 \\
\end{tabular} & 1 & 682.2 & 340.0 & 566.4 & 427.7 & 1 & 313.6 & \begin{tabular}{|l|}
714.4 \\
\end{tabular} & 1 \\
\hline & Mean. & I & 416.8 & 353.5 & I & 589.8 & 79.7 & 484.4 & 238.4 & I & 76.4 & 579.2 & I \\
\hline & Low. & 1 & 144.2 & 234.2 & I & 497.4 & 0.0 & 402.3 & 49.2 & 1 & 0.0 & 443.9 & I \\
\hline \multirow{3}{*}{ Comp4 } & pp. & I & 123.9 & 69.6 & 1 & 90.8 & 80.8 & 76.9 & 94.5 & 1 & 93.5 & 87.4 & I \\
\hline & Mean. & I & 79.6 & 56.3 & I & 80.5 & 38.5 & 67.8 & 63.7 & I & 55.0 & 72.4 & I \\
\hline & ow. & 1 & 35.3 & 43.0 & 1 & 70.2 & 0.0 & 58.6 & 33.0 & 1 & 16.4 & 57.3 & 1 \\
\hline \multirow{3}{*}{ Comp5 } & pp. & I & 856.5 & \begin{tabular}{|l|}
147.5 \\
\end{tabular} & 1 & 282.1 & 516.3 & 231.1 & 543.2 & 1 & 471.9 & 219.6 & 1 \\
\hline & Mean. & I & 506.7 & 105.1 & I & 249.3 & 182.2 & 201.9 & 300.3 & I & 167.4 & 171.5 & I \\
\hline & ow. & I & 156.9 & 62.6 & I & 216.4 & 0.0 & 172.7 & 57.5 & I & 0.0 & 123.4 & I \\
\hline \multirow{3}{*}{ Comp6 } & & 1 & 2520 & 5252.7 & 1 & 7003.2 & 14270.6 & 4620.7 & & 1 & 13729.4 & 6506.5 & 1 \\
\hline & Mean. & I & 16953.7 & 3965.9 & I & 6007.2 & 6386.2 & 3735.8 & 9969.7 & I & 6545.6 & 5048.5 & I \\
\hline & Low. & I & 8699.4 & 2679.2 & I & 5011.1 & & 2850.8 & 4239.0 & I & & 3590.4 & I \\
\hline \multirow{3}{*}{ Comp7 } & Upp. & I & 451.6 & \begin{tabular}{|l|}
85.9 \\
\end{tabular} & 1 & 76.4 & 258.8 & 49.0 & 353.5 & 1 & 324.0 & 91.5 & 1 \\
\hline & Mean. & I & & 71.4 & I & 65.2 & & 39.1 & 236.4 & I & 177.2 & 75.1 & I \\
\hline & ow. & I & 114.2 & 56.9 & I & 54.0 & 0.0 & 29.2 & 119.3 & I & 30.4 & 58.7 & I \\
\hline \multirow{3}{*}{ Comp8 } & & I & & 1617.5 & I & 1438.7 & & \begin{tabular}{|l|}
923.9 \\
\end{tabular} & & 1 & 6099.7 & 1723.0 & 1 \\
\hline & Mean. & I & 5681.3 & 1345.2 & I & 1227.9 & 2154.8 & 736.7 & 3652.9 & I & 3567.5 & 1414.5 & I \\
\hline & Low. & I & & 1072.9 & I & 1017.1 & & 549.4 & & I & 1035.3 & 1106.0 & I \\
\hline \multirow{3}{*}{ Comp9 } & Upp. & I & 1112.9 & 267.4 & I & 541.5 & 664.9 & 272.4 & 9912.5 & 1 & 651.6 & \begin{tabular}{|l|}
376.7 \\
\end{tabular} & 1 \\
\hline & Mean. & I & & 199.3 & I & 488.9 & 280.9 & 225.6 & & I & 301.7 & 299.7 & I \\
\hline & Low. & I & 308.8 & 131.3 & I & 436.2 & 0.0 & 178.8 & 354.3 & 1 & 00 & 222.6 & I \\
\hline \multirow{3}{*}{ Comp10 } & & 1 & & 162.2 & 1 & 228.4 & & 158.2 & & 1 & 502.5 & 245.5 & 1 \\
\hline & ean. & I & 579.9 & 119.8 & I & 195.6 & 203.7 & 129.0 & 287.7 & I & 230.6 & 197.5 & I \\
\hline & Low. & I & 267.5 & 77.4 & 1 & 162.8 & & 99.8 & 70.9 & 1 & 0.0 & 149.4 & 1 \\
\hline \multirow{3}{*}{ Comp11 } & Upp. & I & 725.3 & 99.6 & I & 102.5 & 484.6 & 75.3 & 511.8 & I & 484.2 & \begin{tabular}{|l|}
68.5 \\
\end{tabular} & I \\
\hline & Mean. & I & 488.1 & 82.1 & I & 88.9 & 258.1 & 63.2 & 347.1 & I & 277.8 & 48.6 & I \\
\hline & Low. & I & 250.9 & 64.5 & I & 75.3 & 31.5 & 51.2 & 182.5 & I & 71.4 & 28.7 & I \\
\hline \multirow{3}{*}{ Comp12 } & pp. & 1 & 1147.6 & 1 & 1 & I & 749.4 & I & 871.1 & 1 & 850.1 & 1 & I \\
\hline & Mean. & I & 684.8 & I & I & I & 307.3 & I & 549.8 & I & 447.3 & I & I \\
\hline & Low. & 1 & 221.9 & 1 & 1 & 1 & 0.0 & 1 & 228.5 & 1 & 44.5 & 1 & 1 \\
\hline \multirow{3}{*}{ Comp13 } & Upp. & 1 & 79.4 & 13.7 & I & 26.2 & 47.9 & 21.4 & 50.4 & 1 & 43.8 & 20.4 & I \\
\hline & Mean. & I & 47.0 & 9.7 & I & 23.1 & 16.9 & 18.7 & 27.9 & I & 15.5 & 15.9 & I \\
\hline & Low. & I & 14.5 & 64.5 & I & 75.3 & 0.0 & 51.2 & 5.3 & I & 0.0 & 28.7 & I \\
\hline
\end{tabular}




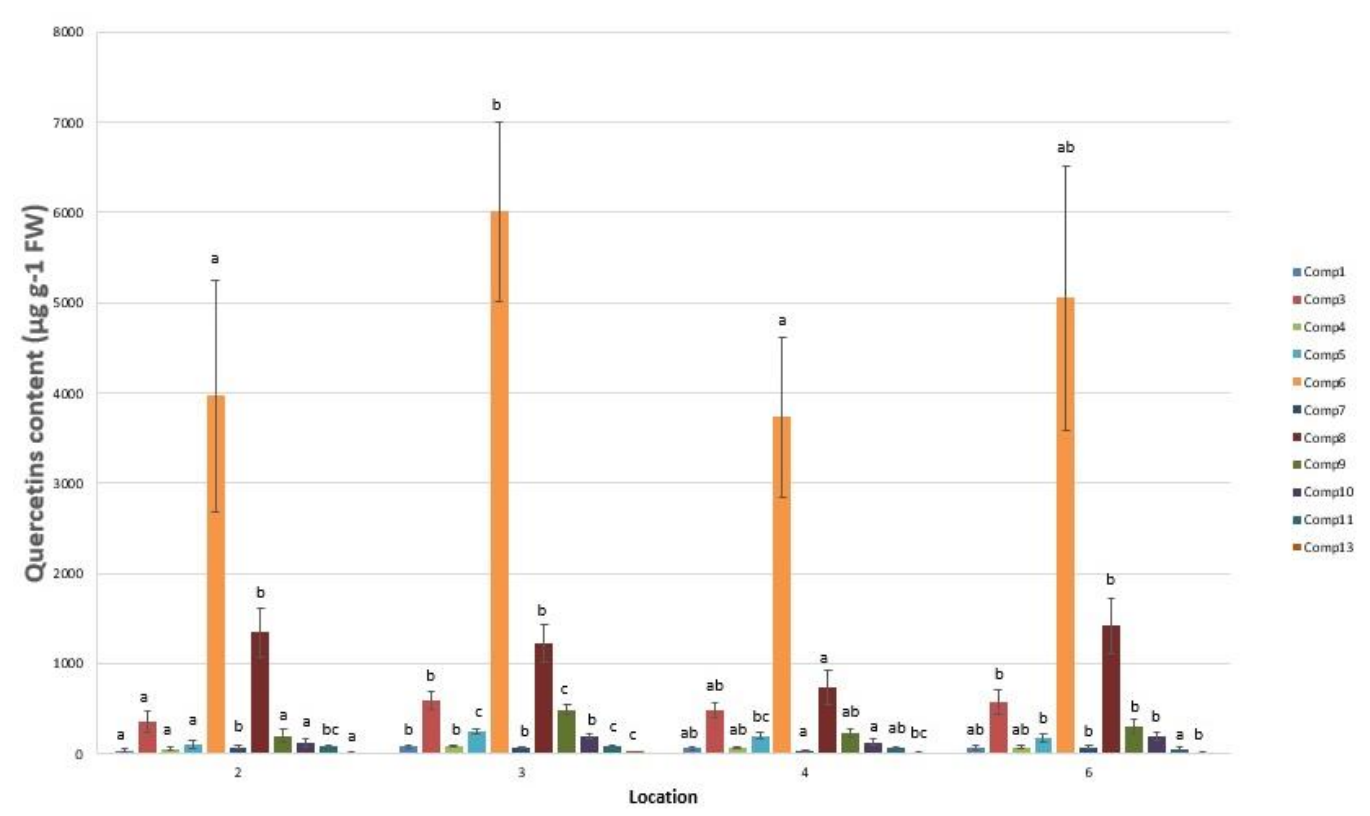

Figure 11. Mean values, upper and lower quercetin content limits in cyclamen leaves collected in spring at various sampling locations $(2=$ Above Barnik, $3=$ Below Barnik, $4=$ Above Draga, $6=$ Kamen zid). With a 95\% confidence interval and $P \leq 0.05$. Characters $a, b$ and $c$ are used to mark statistically significant differences in quercetin content between individual locations $($ Comp1 $=$ Quercetin di rhamnosyl hexoside, Comp3 = Myricetin-3-rutinoside,

Comp4 = Myricetin-hexoside, Comp5 = Kaempferol dirhamnosyl hexoside,

Comp6 $=$ Quercetin-3-rutinoside, $\boldsymbol{C o m p 7}=$ Laricitin-3-O-rutinoside, Comp8 $=$ Myricetin-3rhamnoside, $\boldsymbol{C o m p 9}=$ Quercetin-3-galactoside, Comp10 $=$ Kaempferol 3-rutinoside,

Comp11 = Isorhamnetin-3-rutinoside, Comp13 = Neohesperidoside $)$

In late summer cyclamen leaves collected at different locations, the predominant compounds by quantity in all locations were quercetin di rhamnosyl hexoside2 $\left(7846.6 \pm 2951.2 \mu \mathrm{g} \mathrm{g}^{-1}\right)$, quercetin-3-rutinoside $\left(10467.4 \pm 3006.9 \mu \mathrm{g} \mathrm{g}^{-1}\right)$, and myricetin-3-rhamnoside $\left(3974.9 \pm 1030.2 \mu \mathrm{g} \mathrm{g}^{-1}\right)$. A comparison of specific quercetin content based on location of leaf collection showed statistically significant differences only for myricetin-3-rutinoside and quercetin-3-rutinoside, specifically for the former between locations Goteniška gora and Below Barnik, Goteniška gora and Above Draga, and for the later between locations Goteniška gora and Below Barnik, and Goteniška gora and Goteniški Snežnik (Fig. 12).

\section{Discussion}

Anthocyanin synthesis represents an immediate reaction to increased sunlight intensity, since they act as protection against harmful UV-B radiation (Gould et al., 2002; Steyn et al., 2002; Huges et al., 2007; Huges, 2011). Anthocyanin content can therefore be a good indicator of the level of adaptation or response of originally shady plants to increased radiation intensity, which can be the result of forest gap formation.

In present study, the results confirmed the assumption that spring cyclamen leaves from all sampling locations contain lower anthocyanin quantities than late summer leaves. Plants on forest gaps are not yet exposed to such strong solar radiation during spring than in late summer (Turton, 1991; Brown et al., 1994). Higher anthocyanin 
quantity in late summer probably leads to protection against increased radiation in late summer. In terms of specific anthocyanin content, leaves collected on gaps in spring and late summer contained the highest quantity of anthocyanin malvidin-3,5diglucoside, as confirmed to be the predominant anthocyanin of $C$. purpurascens regardless of season and population (Osterc et al., 2014, 2017). The low anthocyanin content in leaves from Above Draga (youngest gap) could be explained by the fact that this forest gap is youngest, and that plants are not yet completely adapted to the increased radiation intensity, in comparison to plants that have been growing in open surfaces for some time, such as those at location Above Barnik. The latter is also facing SE and therefore distinctly exposed to strong solar radiation for most of the day. The local cyclamen population Above Draga is the most abundant in comparison to other locations. At other locations, populations are smaller, with individual cyclamen specimens growing only occasionally. As early as spring, these rare specimens already have a higher anthocyanin content and are optimally adapted to solar radiation exposure. We can thus suggest that specimens adapted from the time of forest gap formation to the time of sampling by increased anthocyanin synthesis, or that the specimens whose leaves were collected for sampling are in fact offspring of those exposed to increased solar radiation at the time of forest gap formation. Most likely, only the offspring with already higher anthocyanin content, which protect the leaf against excessively strong solar radiation, managed to survive. The latter statement seems more likely, since the study (Osterc et al., 2017) comparing anthocyanin content in wild specimens of common cyclamen, brought and grown further in culture, found unchanged anthocyanin content. Regardless of the changed environmental factors during the move to a new location, with all relocated specimens equal, cyclamen leaves collected at sunny locations contained higher quantities of malvidin-3,5-diglucoside in comparison to cyclamen specimens collected in shady habitats. Therefore, synthesis of specific quantity of anthocyanin persisted for 10 to 12 years after replanting (Osterc et al., 2017). Based on the development and ecology of the common cyclamen, we can suggest that local populations on older forests gaps are in fact not the same specimens that grew there at the time of forest gap formation. Increased anthocyanin quantity thus ensures easier survival with increased solar radiation, which was also proven with two corn genotypes (HOPI and W22) (Pietrini et al., 2002). Genotype HOPI, containing anthocyanins in leaves, could be exposed to higher light intensity with no photooxidation processes detected, as opposed to genotype W22.

With much higher anthocyanin quantity compared with other locations, no differences were shown between leaves collected from Kamen Zid (juvenile phase of beech forest) and on gap Above Barnik, despite the environmental differences of the two locations. One of the reason could lie in the fact that in spring, before beech trees grew leaves (beech tree leaves in this location only developed after sampling), cyclamen leaves on location Kamen Zid were exposed to increased solar radiation (comparing to season with developed beech leaves), and had increased anthocyanin synthesis for protection (Huges et al., 2005; Klančnik et al., 2016). Nevertheless, the young trees on this location are quite dense, and probably the solar radiation is still not so strong; the reason for such anthocyanin content could therefore also be lack of light, with anthocyanins additionally absorbing solar radiation (Chalker-Scott, 1999). Anthocyanin synthesis as a result of low solar radiation is common primarily in tropical understory plants, where the lack of light is more prominent and sun flecks are rarer (Wheldale, 1916; Lee et al., 1979). Species Episcia lilacina Hanst. was found to contain 
anthocyanins primarily in the spongy tissue next to palisade tissue, which as such cannot act as protection, but can only contribute to additional light absorption (Rauch, 2009). To confirm thus hypothesis in our samples - leaves of C. purpurascens additional leaves of specimens from location Kamen Zid should be collected. Using microscopic slides, we could precisely determine the location of anthocyanin accumulation in leaves. In the analysis of late summer samples, differences in content quantities of anthocyanins malvidin-3,5-diglucoside and cyaniding-3-neohesperidoside, specifically only between locations Goteniška gora (oldest gap) and Below Barnik were found. There were no differences for these two anthocyanins in spring samples, based on a comparison with the other three anthocyanins, which only showed differences in spring samples. Therefore two groups of anthocyanins could be observed: the first, with statistically significant differences in content during spring between the youngest gap (Above Draga) and the other two (Above Barnik, Below Barnik); and the second group of anthocyanins, with statistically significant differences during late summer, specifically only between the gaps Goteniška gora and Above Barnik. The leaves collected at Goteniška gora contained twice as much anthocyanins malvidin-3,5diglucoside and cyaniding-3-neohesperidoside. The difference in content between the leaves from these two forests gaps likely is not a results of exposure duration (considering the gap formation) to increased radiation, since the gaps do not differ significantly in terms of formation time. Furthermore, they also do not differ significantly in terms of anthocyanin content during spring. We therefore assume that the late summer differences in contents of malvidin-3,5-diglucoside and cyanidin 3neohesperidoside are the result of temperature fluctuations and high exposure to UV-B radiation (Fig. 4). Anthocyanins in plants also have a protective role against low temperatures and frost (Wheldale, 1916; Mendez et al., 1999). These two anthocyanins could be the ones in $C$. purpurascens leaves that act as protection against low temperatures, since differences in content occurred only in late summer, specifically between locations that differ significantly in size and exposure. The location of Goteniška gora has the largest and most exposed gap, with consequently greater temperature fluctuations (Buajan et al., 2016), which can be noticed there already in late summer, when early mornings can be quite cold (Fig. 2). The gap Below Barnik is the smallest, with lower temperature fluctuations due to the surrounding forest stand. At the latter location, cyclamen leaves have not yet been exposed to such low temperatures that would require protection.

Three quercetins, quercetin-di-rhamnosyl hexoside2, quercetin-3-rutinoside, and myricetin-3-rhamnoside, with much higher contents among all quercetins in $C$. purpurascens leaves taken both in spring and late summer were found. Similar results also were reported by Osterc et al. (2014, 2017). Although all five anthocyanin contents were higher in late summer than those in spring, not all quercetin showed differences between spring and late summer. Based on this we can conclude that all quercetins do not have the same function in cyclamen leaves, as was already determined for other plants, where they for example act as a protection against insects and other pathogens (Mierziak et al., 2014). Also in cyclamen leaves probably some of them do not directly participate in the protection of the leaf against increased UV radiation. In spring, statistically significant differences in content for as many as 8 quercetins (quercetin di rhamnosyl hexoside1, myricetin-3-rutinoside, myricetin-hexoside, kaempferol dirhamnosyl hexoside, quercetin-3-rutinoside, quercetin-3-galactoside, kaempferol 3rutinoside, neohesperidoside) between locations Above Barnik and Below Barnik was 
found. Based on analyses conducted, there is no explanation what causes such differences. Statistically significant differences between other locations were also found, but were quite varied based on the type of quercetin. In spring the leaves from location Above Draga contained a higher quantity of quercetin myricetin-3-rhamnoside than the leaves from locations Above Barnik, Below Barnik, and Kamen zid. Quercetins represent the immediate response and also the main protection against UV-B radiation (Mierziak et al., 2014). This specific quercetin probably provides specific quercetin provides the first protection against radiation for $C$. purpurascens leaves in spring, since the leaves at this location in spring contain the lowest quantity of anthocyanins, compared to leaves from other locations.

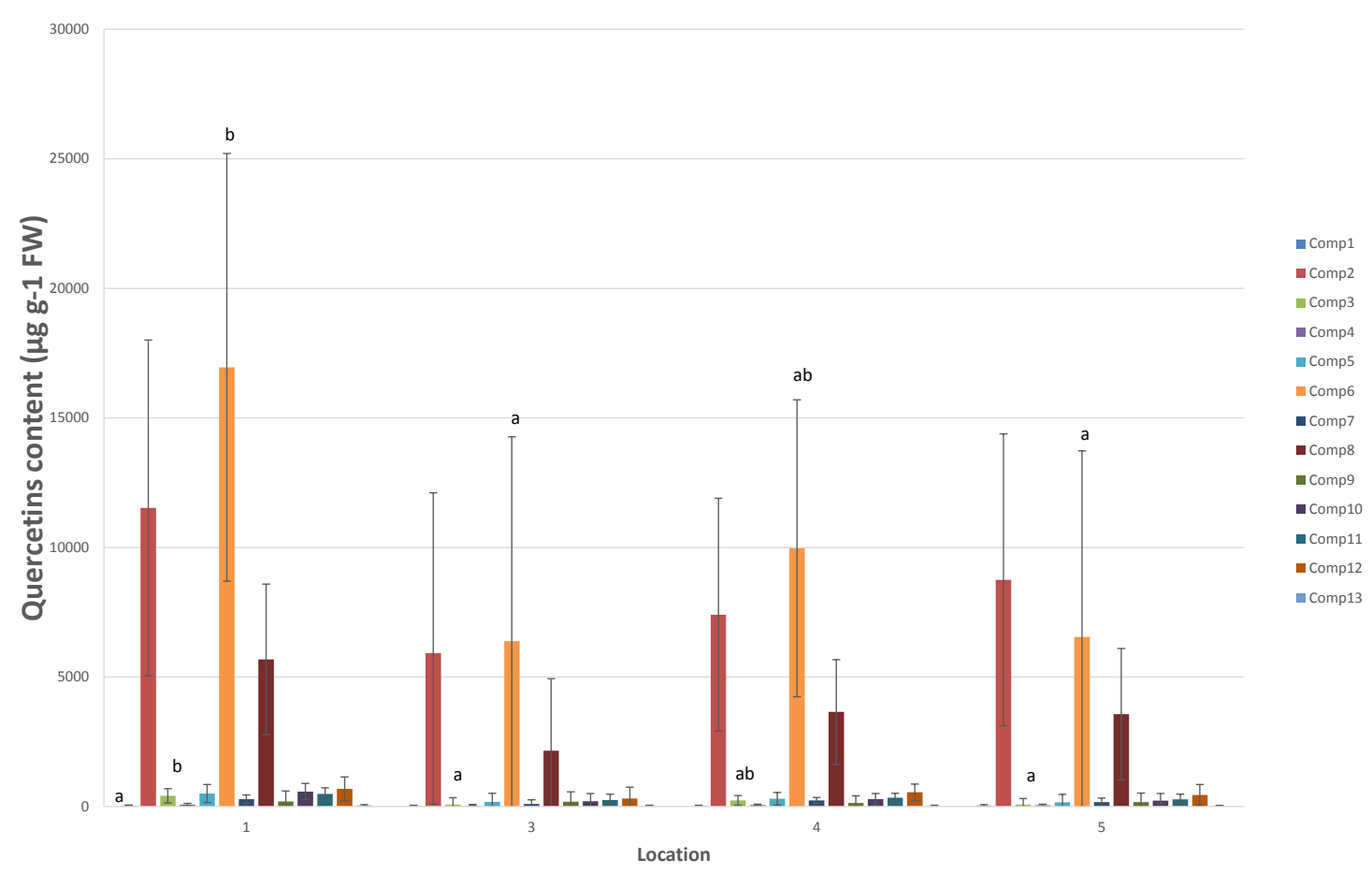

Figure 12. Mean values, upper and lower quercetin content limits in cyclamen leaves collected in late summer at various sampling locations $(1=$ Goteniška gora, $3=$ Below Barnik,

$4=$ Above Draga, 5 = Below Goteniški Snežnik). With a 95\% confidence interval and $P \leq 0.05$.

Character $a$ and $b$ is used to mark statistically significant differences in quercetin content between individual locations $($ Comp1 $=$ Quercetin di rhamnosyl hexoside, Comp2 $=$ Quercetin di rhamnosyl hexoside2, Comp3 = Myricetin-3-rutinoside, Comp4 $=$ Myricetin-hexoside,

Comp5 $=$ Kaempferol dirhamnosyl hexoside, Comp6 $=$ Quercetin-3-rutinoside,

Comp7 = Laricitin-3-O-rutinoside, $\operatorname{Comp8}=$ Myricetin-3-rhamnoside, Comp9 $=$ Quercetin-3galactoside, Comp10 = Kaempferol 3-rutinoside, Comp11 = Isorhamnetin-3-rutinoside, Comp12 = Quercetin-3-rhamnoside, Comp13 $=$ Neohesperidoside $)$

A 60-min exposure to UV-B radiation is enough to activate intensive quercetin synthesis (Shourie et al., 2014). Our results from location Kamen zid confirm this characteristic of quercetins. Leaves from these locations contained a statistically significant lower quantity of eight quercetins, compared to the leaves collected at other locations. Location Kamen zid is characterised as a juvenile phase of beech forest, and is therefore the shadiest location. Because UV-B radiation is lower there (Fig. 4), the 
leaves do not require immediate protection, and the quercetin content is therefore lower. In late summer, results showed an interesting turnaround in statistically significant differences of quercetin content. Only for two quercetins (myricetin-3-rutinoside and quercetin-3-rutinoside) the differences were measured, where the leaves from Goteniška gora contained the highest quantity of the two quercetins, which significantly differed from content in leaves from locations Below Barnik, Above Barnik, and Goteniški Snežnik. The highest content of the two quercetins in leaves from this location could be explained by their synthesis being indirectly dependant on the accumulated UV-B radiation (Sullivan and Teramura, 1988), as this gap is the largest and most exposed to solar radiation (Fig. 1). Quercetins therefore additionally protect the leaves on this location against radiation.

\section{Conclusion}

The cyclamens from at Above Draga have yet adapted to the increased radiation intensity due to the pretty recent formation of forest gap, as shown from their lower anthocyanin content in spring but not in summer, comparing with other locations. In the study, a wide range of anthocyanin functions was confirmed. In addition to protecting the plant against strong solar radiation, they can assist in additional absorption of light in shady plants. This was established with the statistically significant higher anthocyanin content in spring cyclamen leaves from location Kamen Zid - juvenile phase of beech forest. This is actually the shadiest location (and actually the oldest forest gap). Furthermore, the function of anthocyanins as protection against low temperatures was confirmed, specifically in cyclamen leaves at the largest and most exposed gap Goteniška gora. At this location, leaves in late summer contained a statistically significant higher quantity of anthocyanins than leaves on the smallest, less exposed gap. Higher quercetin content at the youngest gap (Above Draga), with leaves not adapted to permanent sun exposure, indicates that quercetin acts as the first immediate protection against UV-B. In late summer, the quercetin content that stands out is the one in leaves from the largest gap, which is most exposed to solar radiation for the longest duration. The reason for this is increased synthesis of anthocyanin and quercetin due to UV-B radiation accumulation. Based on study results, it is confirmed that local populations of common cyclamen were capable of surviving in forest gaps only because of increased anthocyanin and quercetin content, which protect plants against strong solar radiation. For a more detailed examination of anthocyanin accumulation in common cyclamen leaf tissues, microscopic slides would have to be prepared in the future.

\section{REFERENCES}

[1] Agati, G., Azzarello, E., Pollastri, S., Tattini, M. (2012): Flavonoids as antioxidants in plants: location and functional significance. - Plant Science 196: 67-76.

[2] Bavcon, J. (2009): Common Cyclamen (Cyclamen purpurascens Mill.) and Its Diversity in Slovenia. - Botanic Garden, Department of Biology, Biotechnical Faculty, Ljubljana.

[3] Brown, M. J., Parker, G. G., Posner, N. E. (1994): A survey of ultraviolet-B radiation in forest. - Journal of Ecology 82: 843-854.

[4] Buajan, S., Jinfu, L., Zhongsheng, H., Xueping, F., Muhammad, A., Farooq, T. H. (2016): Effect of gap size on the dynamic of micro environments during the daytime at 
Castanopsis kawakamii Natural Reserve Forest, Sanming City, China. - Environment and Natural Resources Journal 14(2): 30-34.

[5] Caldwell, M. M., Robberecht, R., Flint, S. D. (1983): Internal filters: prospects for UVacclimation in higher plants. - Physiologia Plantarum 58(3): 445-450.

[6] Chalker-Scott, L. (1999): Environmental significance of anthocyanins in plant stress responses. - Photochemistry and Photobiology 70(1): 1-9.

[7] Chazdon, R. L., Pearcy, R. W. (1991): The importance of sunflecks for forest understory plants. - Bioscience 41(11): 760-766.

[8] Collins, B., Pickett, S. T. A. (1988): Demographic responses of herb layer species to experimental canopy gaps in a northern hardwoods forests. - Journal of Ecology 76: 437450.

[9] Cooper-Driver, G. A. (2001): Contributions of Jeffery Harborne and co-workers to the study of anthocyanins. - Photochemistry 56: 229-236.

[10] Gould, K. S., Markham, K. R., Smith, R. H., Goris, J. J (2000): Functional role of anthocyanins in the leaves of Quintinia serrata A. Cunn. - Journal of Experimental Botany 51: 1107-1115.

[11] Gould, K. S., McKelvie, J., Markham, K. R. (2002): Do anthocyanins function as antioxidants in leaves? Imaging of $\mathrm{H}_{2} \mathrm{O}_{2}$ in red and green leaves after mechanical injury.

- Plant, Cell and Environment 25: 1261-1269.

[12] Grey-Wilson, C. (1988): The Genus Cyclamen. A Kew Magazine Monography. Chritopher Helm/Timber, London.

[13] Grey-Wilson, C. (2002): Cyclamen: A Guide for Gardeners, Horticulturists and Botanists. New Edition. - BT Batsford, London.

[14] He, F., Mu, L., Yan, G.-L., Liang, N.-N., Pan, Q.-H., Wang, J., Reeves, M. J., Duan, C.Q. (2010): Biosynthesis of anthocyanins and their regulation in colored grapes. Molecules 15: 9057-9091.

[15] Hughes, N. M. (2011): Winter leaf reddening in 'evergreen' species. - New Phytologist 190: 573-581.

[16] Hughes, N. M., Neufeld, H. S., Burkey, K. O. (2005): Functional role of anthocyanins in high-light winter leaves of the evergreen herb Galax urceolata. - New Phytologist 168: 575-587.

[17] Hughes, N. M., Morley, C. B., Smith, W. K. (2007): Coordination of anthocyanin decline and photosynthetic maturation in juvenile leaves of three deciduous tree species. - New Phytologist 175(4): 675-585.

[18] Ishizaka, H., Yamada, H., Sasaki, K. (2002): Volatile compounds in the flowers of Cyclamen persicum, C. purpurascens and their hybrids. - Scientia Horticulturae 94: 125135.

[19] Kelemen, K., Mihók, B., Gálhidy, L. (2012): Dynamic response of herbaceous vegetation to gap opening in a central European beech stand. - Silva Fennica 46: 53-65.

[20] Kerner, V. M. (1894): The Natural History of Plants. - Blackie \& Son, London.

[21] Klančnik, K., Levpušček, M., Gaberščik, A. (2016): Variegation and red abaxial epidermis define the leaf optical properties of Cyclamen purpurascens. - Flora 224: 8795.

[22] Kordiš, F. (1993): Dinaric Beech-Fir Forests in Slovenia. - Department of Forestry, Biotechnical Faculty, Ljubljana.

[23] Lambers, H., Chapin III, F. S., Pons, T. L. (2008): Plant Physiological Ecology, Second Edition. - Springer Science + Business Media, New York.

[24] Lee, D. W., Lowry, J. B., Stone, B. C. (1979): Abaxial anhocyanin layer in leaves of tropical rain forest plants: enhancer of light capture in deep shade. - Biotropica 11(1): 7077.

[25] Matthew, B. (2013): Genus Cyclamen in Science, Cultivation, Art and Culture. - Royal Botanic Gardens Kew, Richmond. 
[26] Mendez, M., Gwynn Jones, D., Manetas, Y. (1999): Enhanced UV-B radiation under filed conditions increases anthocyanin and reduces the risk of photoinhibition but does not affect growth in the carnivorous plant Pinguicula vulgaris. - New Phytologist 144: 275-282.

[27] Middleton, L. (2001): Shade-tolerant flowering plants: adaptations and horticultural implications. - Acta Horticulturae 552: 95-102.

[28] Mierziak, J., Kostyn, K., Kulma, A. (2014): Flavonoids as important molecules of plant interactions with the environment. - Molecules 19: 16240-16265.

[29] Mihók, B., Gálhidy, L., Kenderes, K., Standovár, T. (2007): Gap regeneration patterns in a semi-natural beech forest stand in Hungary. - Acta Silvatica \& Lignaria Hungarica 3: $31-45$.

[30] Osterc, G., Cunja, V., Mikulič Petkovšek, M., Schmitzer, V., Štampar, F., Bavcon, J. (2014): Foliage identification of different autochthonous common cyclamen genotypes (Cyclamen purpurascens Mill.) using various biochemical parameters. - Scientia Horticulturae 173: 37-44.

[31] Osterc, G., Mikulič Petkovšek, M., Štampar, F., Ravnjak, B., Bavcon, J. (2017): Impact of specific environmental characteristics of the site origin (shady, sunny) on anthocyanin and flavonol contents of replanted plants at common cyclamen (Cylamen purpurascens Mill.). - Acta Physiologiae Plantarum 39(64): 1-10.

[32] Peterken, G. F. (1996): Natural Woodland, Ecology and Conservation in Northern Temperate Regions. - Cambridge University Press, New York.

[33] Pietrini, F., Iannelli, M. A., Massacci, A. (2002): Anthocyanin accumulation in the illuminated surface of maize leaves enhances protection from photo-inhibitory risks at low temperature, without further limitation to photosynthesis. - Plant, Cell \& Environment 25(10): 1251-1295.

[34] Podani, J. (2006): Braun-Blanquet's legacy and data analysis in vegetation science. Journal of Vegetation Science 17: 113-117.

[35] Rauch, A. (2009): Leaf colour patterns, vegetative and sexual reproduction of Episcia lilacina (Gesneriaceae). - Diplomarbeit, Universität Wien, Wien.

[36] Schultze, E.-D., Beck, E., Müller-Hohenstein, K. (2005): Plant Ecology. - Springer Verlag, Berlin.

[37] Shourie, A., Tomar, P., Srivastava, D., Chauhan, R. (2014): Enhanced biosynthesis of quercetin occurs as a photoprotective measure in Lycopersicum esculentum Mill. under acute UV-B exposure. - Brazilian Archives of Biology and Technology 57(3): 317-325.

[38] Smith, R. L., Smith, T. M. (2001): Ecology \& Field Biology. - Benjamin Cummings, San Francisco.

[39] Sullivan, J. H., Teramura, A. H. (1988): Effects of ultraviolet-B irradiation on seedling growth in the Pinaceae. - American Journal of Botany 75: 225-230.

[40] Steyn, W. J., Wand, S. J. E., Holcroft, D. M., Jacobs, G. (2002): Anthocyanins in vegetative tissues: a proposed unified function in photoprotection. - New Phytologist 155: 349-361.

[41] Timmins, G. S., Holbrook, N. M., Field, T. S. (2002): Le Rouge et le Noir: Are Anthocyanins Plant Melanins? - In: Gould, K. S., Lee, D. W. (eds.) Anthocyanins in Leaves. Advances in Botanical Research 37. Academic Press, Amsterdam, pp. 18-35.

[42] Turton, S. M. (1991): Solar Radiation Regimes in Rainforest Understoreys, Gaps and Clearings, with Special Reference to Northeast Queensland. Vol. 1. PhD Thesis. - James Cook University, New Queensland.

[43] Wheldale, M. (1916): The Antocyanin Pigments. - Cambridge University, Merton.

[44] Whittaker, R. H. (1975): Communities and Ecosystems. - Macmillan Publishing, New York.

[45] Wraber, M. (1969): Pflanzengeographische Stellung und Gliederung Sloveniens. - Acta Geobotanica 176-199.

[46] Yamasaki, H. (1997): A function of color. - Trends in Plant Sciences 2: 2-7. 